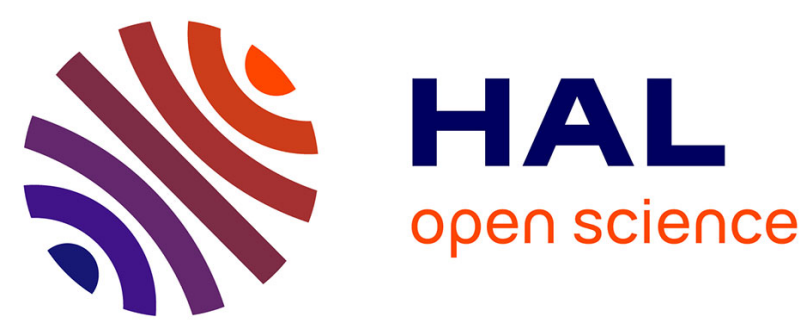

\title{
Imaging the Structure of Macroporous Hydrogels by Two-Photon Fluorescence Microscopy
}

Mohand Chalal, Françoise Ehrburger-Dolle, Isabelle Morfin, Jean-Claude Vial, Maria-Rosa Aguilar de Armas, Julio San Roman, Nimet Bölgen, Erhan Pişkin, Omar Ziane, Roger Casalegno

\section{To cite this version:}

Mohand Chalal, Françoise Ehrburger-Dolle, Isabelle Morfin, Jean-Claude Vial, Maria-Rosa Aguilar de Armas, et al.. Imaging the Structure of Macroporous Hydrogels by Two-Photon Fluorescence Microscopy. Macromolecules, 2009, 42 (7), pp.2749 - 2755. 10.1021/ma802820w . hal-01087830

\section{HAL Id: hal-01087830 https://hal.science/hal-01087830}

Submitted on 26 Nov 2014

HAL is a multi-disciplinary open access archive for the deposit and dissemination of scientific research documents, whether they are published or not. The documents may come from teaching and research institutions in France or abroad, or from public or private research centers.
L'archive ouverte pluridisciplinaire HAL, est destinée au dépôt et à la diffusion de documents scientifiques de niveau recherche, publiés ou non, émanant des établissements d'enseignement et de recherche français ou étrangers, des laboratoires publics ou privés. 
Imaging the structure of macroporous hydrogels by two-photon fluorescence microscopy

\section{Mohand Chalal $^{\text {a,b }}$, Françoise Ehrburger-Dolle ${ }^{\text {a* }}$, Isabelle Morfin ${ }^{a}$, Jean-Claude Vial ${ }^{\text {a }}$, Maria- Rosa Aguilar de Armas ${ }^{\text {, Julio San Roman }}{ }^{c}$, Nimet Bölgen ${ }^{d}$, Erhan Pişkin ${ }^{d}$, Omar Ziane ${ }^{b}$, Roger Casalegno ${ }^{a}$}

${ }^{a}$ Laboratoire de Spectrométrie Physique, UMR 5588, CNRS, Université Joseph Fourier de Grenoble, 38402 Saint Martin d'Hères, France

${ }^{b}$ Laboratoire d'Electronique Quantique, Faculté de Physique, Université des Sciences et de la Technologie Houari Boumediene, USTHB Alger, El-Alia Bab-Ezzouar,16111 Alger, Algérie

${ }^{c}$ Instituto de Ciencia y Tecnología de Polímeros, CSIC and CIBER-BBN, C/ Juan de la Cierva, 3, 28006 Madrid, Spain

${ }^{d}$ Hacettepe University, Chemical Engineering Department and Bioengineering Division, Beytepe, Ankara, Turkey

ABSTRACT: Two-photon fluorescence microscopy (TPFM) usually used to get 3-D pictures of biological systems has been applied here for the first time to macroporous hydrogels prepared by cryogelation ("cryogels"). Unlike environmental scanning electron microscopy (ESEM) which analyzes the surface of swollen samples, TPFM delivers images of successive planes in the depth of the material allowing a 3-D imaging of its structure. The macroporous hydrogels studied were poly( $N$-isopropylacrylamide) (pNIPA), poly(Hydroxyethyl Methacrylate-L-Lactide-Dextran) (pHEMA-LLA-D) and various co-polymeric gels of these two ones. A quantification of the macropore size distribution and the wall thickness and their modification with respect to the ratio NIPA/HEMA-LLA-D or to the temperature, in the case of pNIPA, was readily obtained.

Keywords: Two-photon fluorescence microscopy, macropore size distribution, macroporous hydrogels, cryogels, thermosensitive macroporous gels.

\section{Introduction}

A macroporous polymer gel can be defined as a more or less interconnected network of gel walls and large voids. Such materials present a significant interest from fundamental and application point of view, particularly for biotechnological and biomedical applications ${ }^{1}$, e.g., as scaffolds in tissue engineering ${ }^{2,3}$. In the case of intelligent polymeric materials, which exhibit response to external stimuli such as temperature ${ }^{4}$, the response rate is significantly increased in macroporous gels as compared to bulk gels ${ }^{5}$. Poly( $N$-isopropylacrylamide (pNIPA) gel is a typical example of a temperature sensitive gel as it exhibits a volume phase transition at a critical temperature $\left(\mathrm{T}_{\mathrm{c}}\right)$ of about $34^{\circ} \mathrm{C}$ in aqueous media ${ }^{6}$. Below $\mathrm{T}_{\mathrm{c}}$, pNIPA hydrogels are swollen, hydrated, and hydrophilic. Above $\mathrm{T}_{\mathrm{c}}$, the gels shrink due to the distortion of the hydrophilic/hydrophobic balance in the

\footnotetext{
${ }^{*}$ Corresponding author; e-mail: fehrburg@ @spectro.ujf-grenoble.fr
} 
network structure. The rate of response of pNIPA hydrogels is low due to the formation of a dense "skin layer" of the shrunken gel, which prevents the mass transport of water out of the shrinking gel $^{7}$. In a macroporous structure, however, channels and thin walls facilitate the convective transport of liquid released during the shrinkage of the gel ${ }^{5}$.

Macroporous polymer gels and, particularly, hydrogels are prepared using several techniques ${ }^{1,8}$ as freeze-drying ${ }^{9}$, freeze-extraction and freeze gelation ${ }^{10}$, porogen techniques ${ }^{11}$, phase separation ${ }^{12}$. Macroporous temperature responsive pNIPA gels were also obtained by electron beam irradiation of aqueous polymer solution ${ }^{13}$. The new cryotropic gelation technique, implying synthesis at a subzero temperature, was employed for the preparation of hydrophilic macroporous gels ${ }^{14-17}$ also named cryogels. Because these highly porous polymeric materials can be produced from almost any gel-forming precursor, they exhibit a broad variety of porosities and morphologies ${ }^{18,19}$ allowing the preparation of cryogels with properties tailored for a given application.

It follows that characterization of the macroporosity of the large variety of macroporous polymer gels is essential. Mercury porosimetry, which is the most widely used technique for the determination of the porous volumes and the pore size distributions has been used for dry macroporous gels ${ }^{10-12}$. This method, however, is not suitable for soft materials ${ }^{19}$ and cannot be applied to swollen samples. The macroporous structure can be seen using scanning electron microscopy (SEM) in the dried state and environmental scanning electron microscopy (ESEM) in the swollen state (in water) ${ }^{18,19}$. In most cases, however, SEM and ESEM techniques provide only a qualitative information. Furthermore, these techniques are limited to the surface of the materials and, if it is then possible to clearly observe inhomogeneous structures at the surface, it is impossible to quantify the bulk porosity of the cryogel. On the other hand, Micro-Computed-Tomography ${ }^{20}$ (micro-CT or $\mu$-CT) using X-rays provides a 3-D image of macroporous samples. This method developed for tomographic imaging of small animals and organ biopsies was recently used for analyzing the structure of porous gelatin gels ${ }^{21}$ and poly(2-hydroxyethyl metacrylate) (pHEMA) cryogels $^{22}$ but requires impregnation of an iron chloride solution and freeze-drying under vacuum. Behravesh et $a .^{23}$ have investigated the morphology of swollen macroporous hydrogels by a stereological approach using optical microscopy. Images were obtained on $50 \mu \mathrm{m}$ slices of hydrogels prepared by the techniques used for frozen tissue specimen. The smallest pore size included in the morphometric analysis was $10 \mu \mathrm{m}$.

All the above quoted techniques, except ESEM, do not allow a direct imaging of wet samples. The lack of direct non-intrusive measurements in macroporous hydrogels, incited Appel et $a l^{24}$, in 1998, to use confocal Raman microscopy to estimate the macropore sizes and the thickness of the walls in swollen macroporous gels. These authors were able to investigate the changes in the polymer network structure occurring during heating of a macroporous pNIPA gel up to near the 
volume phase transition temperature $T_{c}$ at which the gel collapses. The variation of polymer concentration between walls and pores is calculated from the $1445 \mathrm{~cm}^{-1}$ Raman band intensity $\left(\mathrm{CH}_{2}\right.$ bending vibration). This techniques probes the macroporous gel structure down to $200 \mu \mathrm{m}$ below the gel surface. Confocal fluorescence microscopy yields 3-D images of objects stained with a fluorophore, e.g., walls in swollen macroporous gels ${ }^{19}$ or of biomedical research specimens ${ }^{25}$. In the most favorable situation, the maximum observable depth is close to $200 \mu \mathrm{m}$. This limit decreases significantly in turbid biological samples. For this reason, two-photon fluorescence microscopy ${ }^{26}$ (TPFM) that enhances the depth of penetration ${ }^{27}$ became a leading tool for imaging cellular and subcellular events within living tissue $\mathrm{e}^{28-31}$.

The aim of the paper is firstly to show that TPFM is a powerful technique for imaging macroporous polymer gels which are naturally turbid and for obtaining, by means of image analysis, a quantitative information about the size distribution of the pores and the walls. This method is used here to investigate the macroporous structure of a series of thermosensitive pNIPA based cryogels, among others. Getting a quantitative information about the macroporosity is essential to assess formation-structure-properties relations. From a more fundamental point of view, the information about the wall thickness and the macropore size obtained by TPFM is necessary to relate the swelling-deswelling mechanism to the size of the gel (wall) and to its meso and nanostructure investigated by Small-Angle X-Ray Scattering (SAXS) ${ }^{32}$.

\section{Materials and experimental method}

2.1. Cryogel samples. Macroporous hydrogels were prepared by free radical cryopolymerization of L-lactide and dextran with 2-hydroxyethyl methacrylate (HEMA) end groups (HEMA-LLA-D) macromer and NIPA. Copolymer compositions of NIPA/HEMA-LLA-D 60/40 and 40/60 (w/w) were prepared. Synthesis of the macromer was described elsewhere ${ }^{33}$. The polymerization reactions were carried out in tubular-shape glass moulds. NIPA monomer and HEMA-LLA-D macromer were dissolved in water to reach a final concentration of $6 \% \mathrm{wt} / \mathrm{v}$. The cross-linker, $N, N^{\prime}-$ methylenebisacrylamide (MBAAm), was dissolved in this mixture (6.6 wt\% of total amount monomer/macromer) and nitrogen was passed-through the solution for $15 \mathrm{~min}$. For initiation of reactions, first $\mathrm{N}, \mathrm{N}, \mathrm{N}^{\prime}, \mathrm{N}^{\prime}-$ Tetramethylethylenediamine (TEMED) (1 wt \%) was added and the solution was cooled in an ice bath for $5 \mathrm{~min}$. Then ammonium persulfate (APS) (1 wt \%) was added and the reaction mixture was stirred about $1 \mathrm{~min} .1 \mathrm{ml}$ of the reaction mixture was injected into the glass mold. The solution in the mold was frozen at $-20^{\circ} \mathrm{C}$ in about $1 \mathrm{~h}$. The frozen samples, cryogels, were kept at $-12^{\circ} \mathrm{C}$ for $16 \mathrm{~h}$ and then thawed at room temperature. The cryogel matrix in each glass mold was washed by passing distilled water to remove any possible unreacted monomers and other ingredients and dried in the air until to reach a constant weight. From a chemical point of 
view, the co-polymers consist of chains of dextran (D) with HEMA-LLA side chains connecting pNIPA chains. The synthesis of plain pNIPA cross-linked with MBAAm and that of pHEMA-LLAD cryogels was earlier described ${ }^{32,33}$. The latter is not thermosensitive. The amplitude of the volume drop at $\mathrm{T}_{\mathrm{c}}$ decreases when decreasing the concentration of NIPA in the copolymers. For FTPM measurements, all cryogels samples were allowed to swell in an aqueous dye solution (concentration of dye $0.25 \mathrm{mg} / \mathrm{l}$ ) during $24 \mathrm{~h}$.

2.2. TPFM measurements. Two-photon fluorescence microscopy (more precisely, two-photon excited fluorescence microscopy) is a nonlinear optical microscopy method in which the nonlinear interactions are confined to the focal region of a focused laser beam. Using a femtosecond pulsed laser, the simultaneous absorption of two photons in a single quantum event yields a localized absorption. The wavelength of the excitation source being nearly twice the absorption wavelength the Rayleigh scattering is lower allowing a deeper penetration in turbid samples. As the setup configuration was already described elsewhere ${ }^{30}$ only the main features are recalled here. The microscope consists of an MRC 1024 scanhead (Biorad, UK), and a BX50WI upright microscope (Olympus, Japan) fitted with a large, home-built, motorized stage ${ }^{30}$. The excitation at $800-\mathrm{nm}$ is provided by a femtosecond Ti:Saphire laser (Tsunami pumped by a Millennia V; Spectra-Physics, Inc., Mountain View, California). The $x-y$ displacement of the focused laser beam is monitored by two rotating mirrors. Planar scans of the fluorescent signals were obtained at successive depths in the sample with a $z$-step between scans of $2 \mu \mathrm{m}$, using the motor drive of the objective. Each image of $512 \times 512$ pixels $^{2}$ corresponds to an area of $200 \mu \mathrm{m} \times 200 \mu \mathrm{m}$ when using a $60 \times$ water-immersion objective (numerical aperture 0.95 ) and $598 \mu \mathrm{m} \times 598 \mu \mathrm{m}$, with a $20 \times$ objective. Acquisition time is 0.9 second per image. The observation depth was changed between images using the motor drive of the objective to obtain a $z$-stack. The dye emission is collected by an external photomultiplier tube in backscattering configuration using a dichroïc filter. Images were displayed, as acquired, by the Biorad operating system. Image processing was made by means of ImageJ (http://rsbweb.nih.gov/ij/). The pixel intensities for each slice were normalized on a scale from 0 to 1 (in 255 steps for a 8-bit acquisition) using the enhanced contrast command of ImageJ. The pore size distribution was determined from the analysis of images obtained at a given $z$-value; 3-D images are visualized by means of ImageJ, by the $z$-projection of the stack of all images.

2.3. Choice of the fluorophore. Concerning the choice of the fluorophore, there are three requirements: (i) the dye must absorb the excitation light following a two-photon absorption process leading to a fluorescence localized at the focal region; (ii) it must be soluble in water and (iii) the dye must be adsorbed by the gel backbone in order to stain the macropore walls. Two potential dyes, fluorescein sodium (uranine) and sulforhodamine B (SRB), belonging to the xanthene dye 
group and used in the Laboratory for intravital $\mathrm{TPFM}^{34}$ are possible candidates. The water solubility of SRB and uranine are $70 \mathrm{~g} / \mathrm{l}$ and $25 \mathrm{~g} / \mathrm{l}$ respectively ${ }^{35}$. Their partition coefficient $\mathrm{K}=\mathrm{C}_{\text {octanol }} / \mathrm{C}_{\text {water }}$ were measured $^{36}$. The values, $\mathrm{K}=0.03$ for $\mathrm{SRB}$ and $\mathrm{K}=0.13$ for uranine, indicate that $\mathrm{SRB}$ is more hydrophilic than uranine.
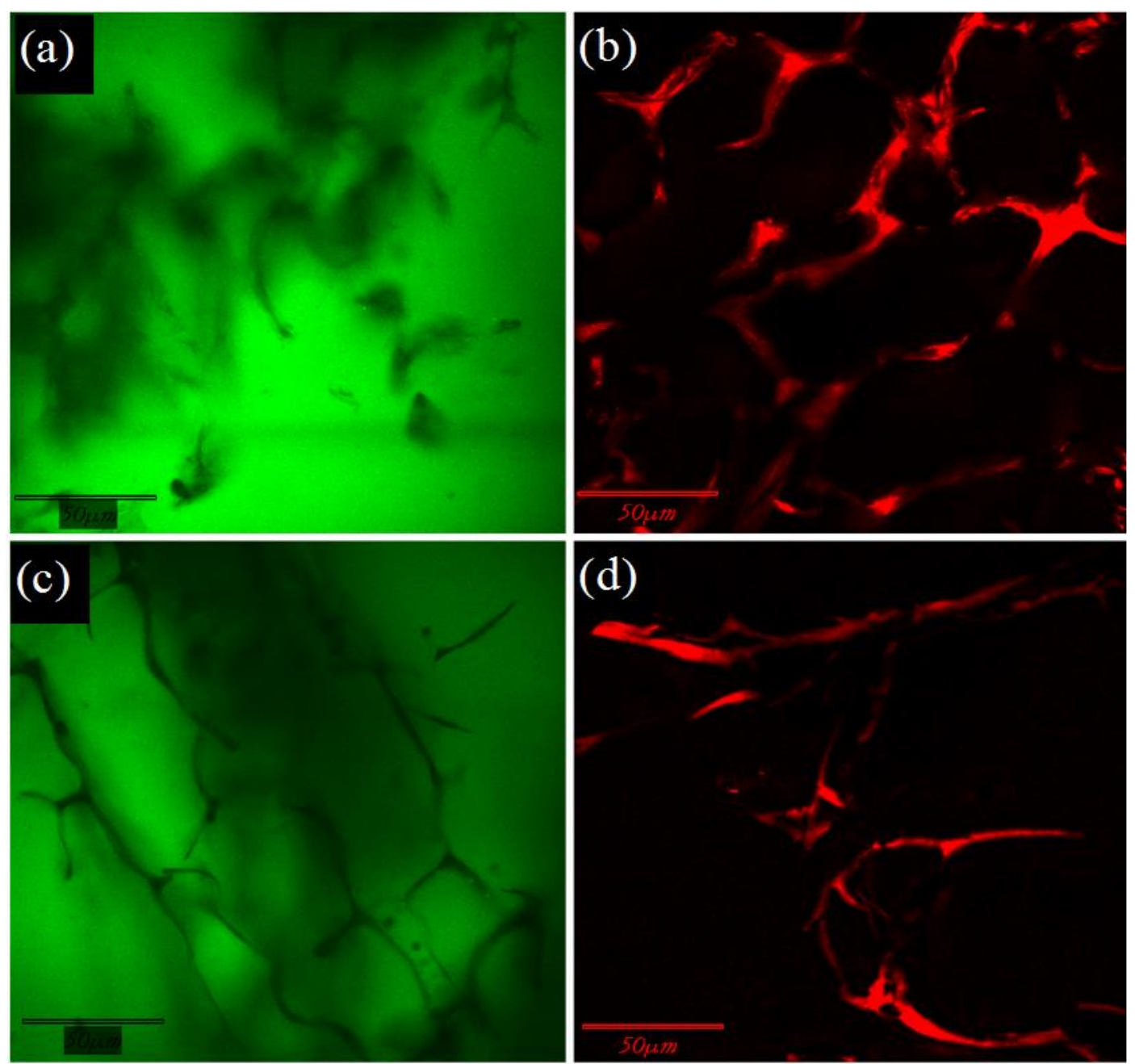

Figure 1. Images of pNIPA (a,b) and pHEMA-LLA-D (c,d) cryogels using two different fluorophores: Uranine (a,c) and SRB (b,d) at $z=100 \mu \mathrm{m}$ (thickness=2 $\mu \mathrm{m}$ ). Scale bar is $50 \mu \mathrm{m}$.

Figure 1 shows that SRB stains the pNIPA gel constituting the macropore walls whereas uranine does not. The same features are observed for all other macroporous hydrogels investigated. Thus, $\mathrm{SRB}$ is used as fluorophore for TPFM of all cryogels investigated. Adsorption of SRB on pNIPA and pHEMA-LLA-D is not surprising. Due to its sulfonate groups, SRB is strongly hydrophilic and expected to be adsorbed on the hydrophilic groups in pNIPA and on the hydroxyl groups of pHEMA. More, two alkyl chains and aromatic cycles confer to SRB a slight lipophilic character. In the field of biological objects, SRB stains basic amino acids of proteins but does not stain albumin which is an acidic protein ${ }^{37}$. In the field of hydrology and transport processes in soils, it was shown that silica (negatively charged surface) adsorbs SRB but not uranine when the opposite is observed 
for the positively charged alumina surface ${ }^{35}$. The results obtained for this series of macroporous polymer gels do not contradict the above reported observations.

\section{Results and discussion}

3.1. Macroporous structure of the cryogels. Figure 2 shows the $z$-projection of stacks of 100 images obtained for the four cryogels investigated. Observation of stacks permits to view the aspect of the walls over a larger extent than in the $2 \mu \mathrm{m}$ thick slices that will be used for the statistical analysis. Qualitatively, the pNIPA (Figure 2a) and the pHEMA-LLA-D cryogels (Figure 2d) do not look alike. In the first one, the walls appear somewhat heterogeneous. In the second one, the walls appear as a crumbled membrane with small holes in it. Conversely, the macropore size seems significantly larger in the pNIPA cryogel than in the pHEMA-LLA-D one. Figures $2 \mathrm{~b}$ and $2 \mathrm{c}$ obtained for the copolymer cryogels suggest that going from pure pNIPA to pure pHEMA-LLA-D induces gradual changes in the structure.
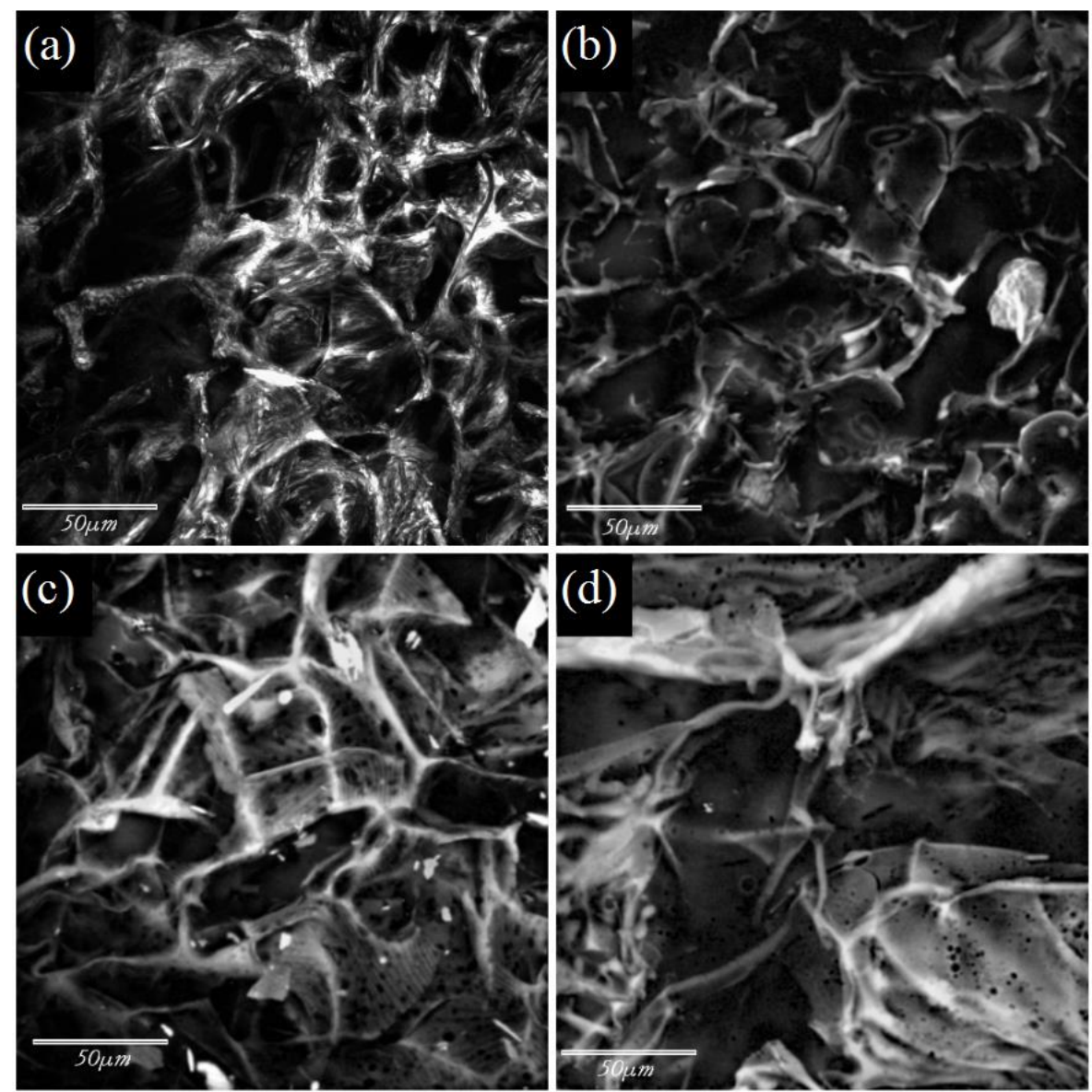

Figure 2. $z$-projection of stacks of images acquired from 15 to $200 \mu \mathrm{m}$ below the surface in steps of $2 \mu \mathrm{m}$ in cryogels pNIPA (a), NIPA-co-HEMA-LLA-D (60/40) (b), NIPA-co-HEMA-LLA-D (40/60) (c), and pHEMA-LLA-D (d). Scale bar is $50 \mu \mathrm{m}$. 

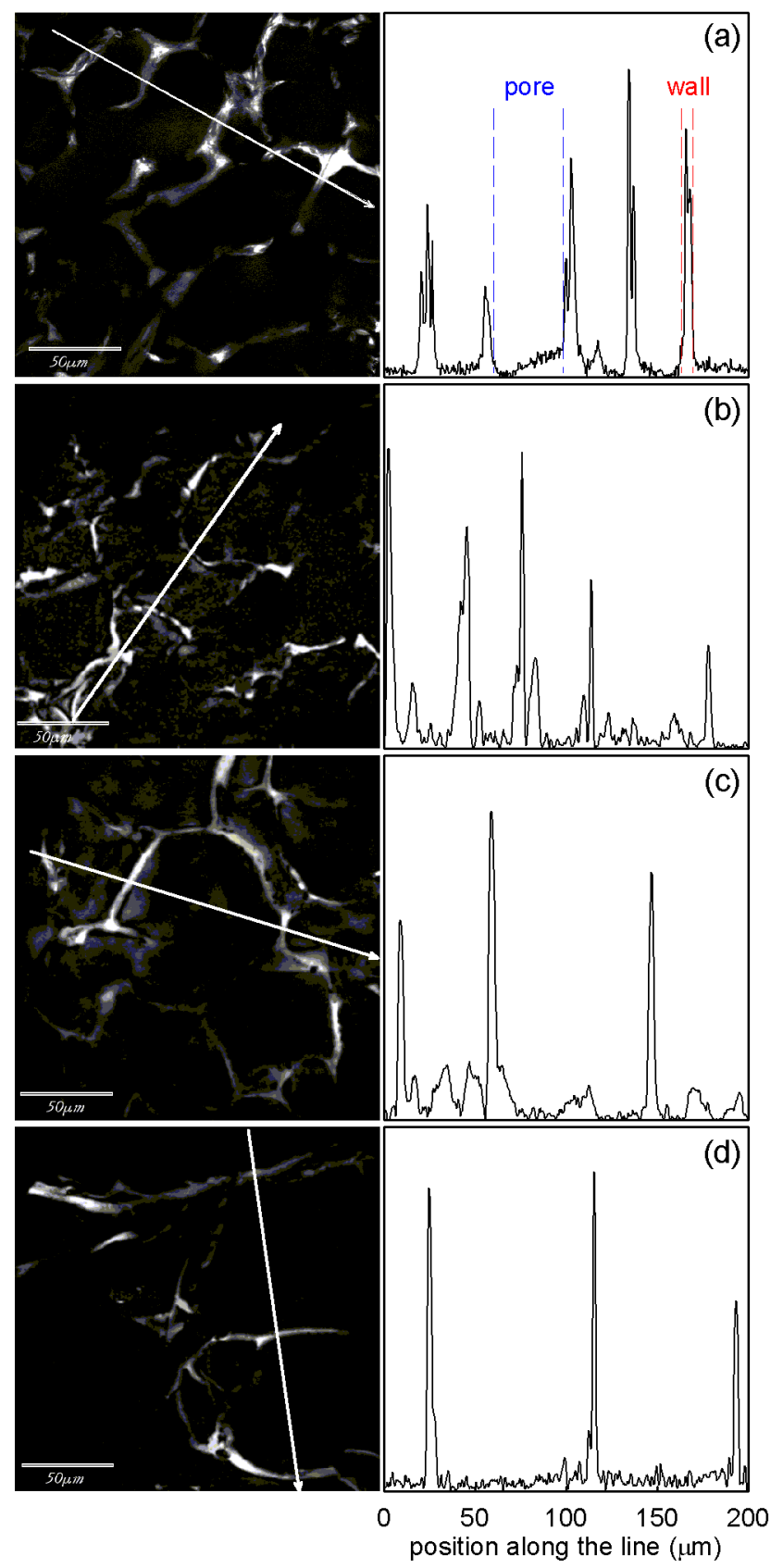

Figure 3. Images (thickness $=2 \mu \mathrm{m}$ ) extracted from the stacks shown in Figure 2 at a given sample depth $z$ (left) and (right) variation of the gray level intensity along the line: pNIPA (a), NIPA-coHEMA-LLA-D (60/40) (b), NIPA-co-HEMA-LLA-D (40/60) (c) and pHEMA-LLA-D (d). Scale bar is $50 \mu \mathrm{m}$.

Quantitative analysis of these observations is made possible by analyzing every images extracted from the stacks shown in Figure 2. Figure 3 shows, on the left, an $x-y$ image obtained at a given depth $z$ (thickness $2 \mu \mathrm{m}$ ) for each cryogel. The variation of the gray level along the line drawn on each image is measured with ImageJ and plotted on the right. Several comments can be drawn from these graphs. Firstly, the thickness of the walls can be estimated. For pNIPA, the wall thickness 
$(12 \pm 2 \mu \mathrm{m})$ is about twice that measured for pHEMA-LLA-D $(6 \pm 2 \mu \mathrm{m})$ and for the two other cryogels.

Looking at the shape of the intensity profile of the pNIPA cryogels it is clearly seen that each peak is generally structured. This feature that becomes less important as the amount of pNIPA decreases is not observed in pHEMA-LLA-D. Fluctuations in the fluorescence intensity (also suggested in Figure $1 b$ ) are related to dye concentration fluctuations. They may originate from structural and/or chemical heterogeneities yielding regions were SRB is not adsorbed. Laser Scanning Confocal Microscope (LSCM) observations of bulk pNIPA gels prepared above $24^{\circ} \mathrm{C}$, reported by Hirokawa et l. $^{38}$ led to a similar comments. Reflection LSCM images revealed bright and dark areas at a 10 $\mu \mathrm{m}$ scale, originating from polymer concentration fluctuations, also shown by Ultra-Small Neutron Scattering (USANS $)^{39}$. Staining the gel with a fluorophore that fluoresces only in an hydrophobic environment (8-anilino-1-naphtalene sulfonic acid ammonium salt, ANSA) permitted to attribute the bright spots (high concentration) to hydrophobic areas in the gels. It is likely that the heterogeneities observed in the $12 \mu \mathrm{m}$ thick walls of the pNIPA cryogels proceed from a similar effect. Further investigation of the macropore walls that would require a higher resolution objective was beyond the scope of the present work. Figure 3 also suggests that the distance between peaks, $i$; e, between macropore walls increases between pNIPA (a) and pHEMA-LLA-D (d). In what follows, the size of the voids between walls will be considered as macropore sizes and measured at the bottom of the peaks.

For the statistical analysis, fluorescence images were acquired by means of the objective $20 \times$ yielding $598 \mu \mathrm{m} \times 598 \mu \mathrm{m}$ images in order to increase the number of voids to be measured. $x-y$ lines are randomly drawn on images acquired at a given depth $z$. An $x-y$ line can also be drawn at increasing depths $z$ leading information about the evolution of the gray level intensity with $z$ as shown in Figure 4. The fluorescence of the solution is taken as the zero level intensity. Accordingly, any peak above this level results from a higher concentration of fluorophore, i.e., from fluorophore adsorbed by the polymer chains in the gel and reveals a wall. The large differences in peak intensity observed in Figure 4 deserve a few comments. Line $\mathrm{A}$ is drawn to outline the variation of the fluorescence intensity during scanning a nearly vertical wall. The intensity drop between 70 and $90 \mu \mathrm{m}$ could result from the diminution of the volume of gel probed by the laser near the lower boundary of the wall. Alternately, the gel density near the boundary could be smaller. The increase of the peak intensity with $z$ along line B would have the same origin: the laser beam is entering a wall. Finally, along line $C$, the intensity becomes zero at $z=84 \mu \mathrm{m}$ when the laser beam start probing the SRB solution in a macropore. The expected attenuation ${ }^{31}$ of the laser beam at increasing $z$ (not shown) manifests itself by an overall decrease of the fluorescence intensity. Unlike the procedure used by Vérant $e t a l .^{31}$, the laser intensity was not increased with $\mathrm{z}$. 


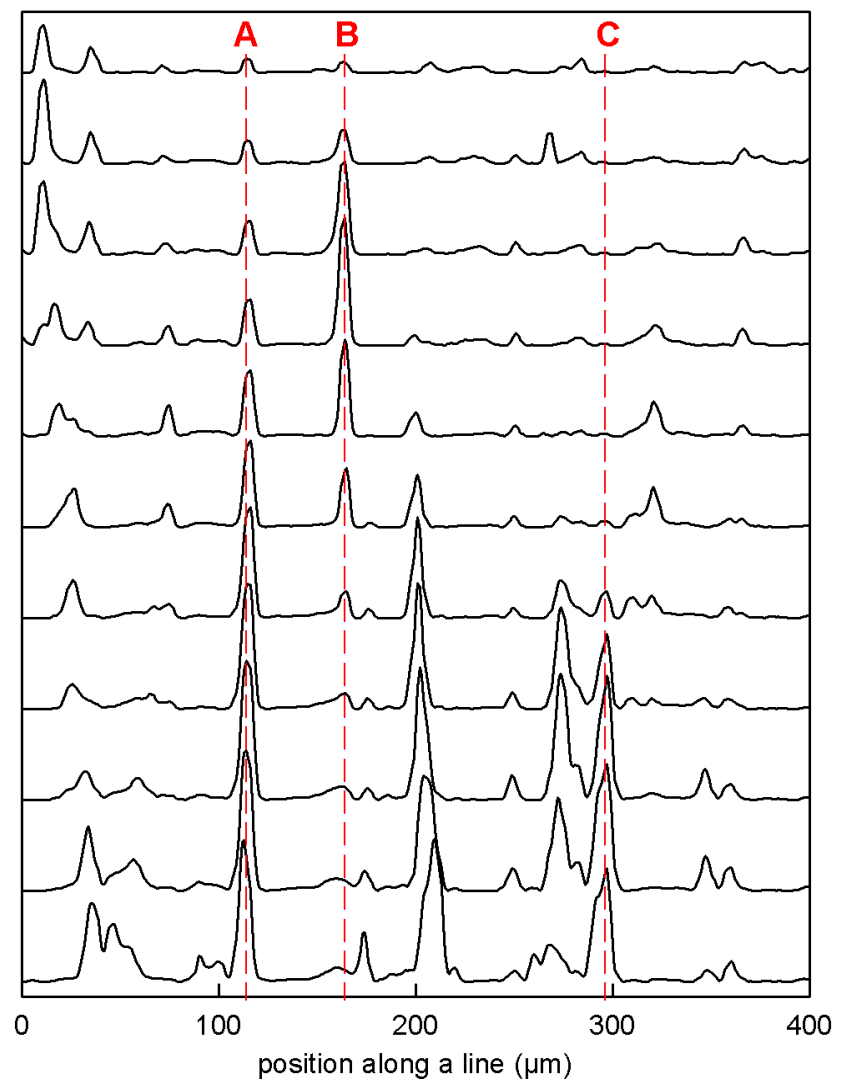

Figure 4. Example of profile of the gray level intensity along a given $x-y$ line at increasing depths (step $=2 \mu \mathrm{m}$ ) from $z=70 \mu \mathrm{m}$ (bottom) to $z=90 \mu \mathrm{m}$ (top) for pNIPA cryogel. The curves were shifted along the $y$-axis and the $y$-scale is 8 times larger than in Figure 3.

The pore size distributions plotted in Figure 5 result from analysis of the intensity profiles along $x-y$ lines randomly drawn in $z$-planes, $z$ varying between 30 and $200 \mu \mathrm{m}$. Depending on the order of magnitude of the void sizes, 250 (when the sample displays very large pores) to 400 void spaces are considered for the statistical analysis. The histograms confirm that the macropores developed by cryogelation of pNIPA are smaller than those developed by pHEMA-LLA-D. The pore sizes in pNIPA are rather monodisperse not exceeding $75 \pm 5 \mu \mathrm{m}$ with a maximum at $37.5 \pm 2.5 \mu \mathrm{m}$. Conversely the pore sizes in pHEMA-LLA-D have a bi-modal distribution, this cryogel developing different types of macropores. For the smaller ones the maximum of the distribution appears at $24 \pm 5 \mu \mathrm{m}$ and at $185 \pm 5 \mu \mathrm{m}$ for the larger ones. Observation of the image shown in Figure $2 \mathrm{~d}$ suggests that the small pores contribution corresponds to surface cavities in a crumbled wall whereas the right side of the distribution would characterize inter-wall distances, i.e., macropores. For the copolymers NIPA-co-HEMA-LLA-D, the upper limit of the pore sizes distribution begins to increase with decreasing concentration of pNIPA to $105 \pm 10 \mu \mathrm{m}$ and $140 \pm 10 \mu \mathrm{m}$ respectively for the $60 / 40$ and the 40/60 NIPA/HEMA-LLA-D ratio. 


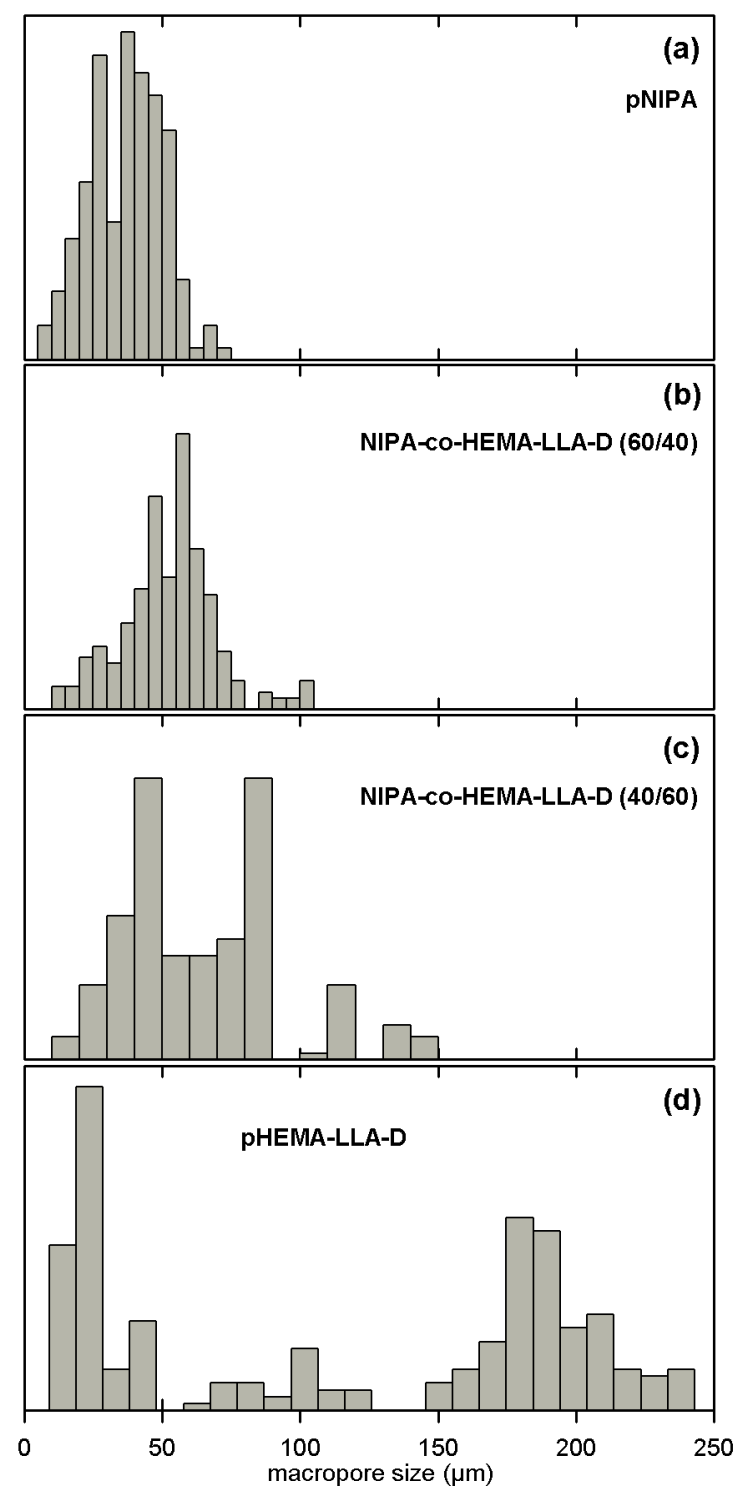

Figure 5. Macropore size distribution in the different cryogels: pNIPA (a), NIPA-co-HEMA-LLAD (60/40) (b), NIPA-co-HEMA-LLA-D 40/60 (c) and pHEMA-LLA-D (d).

The effects of the decrease in NIPA concentration on the macroporous structure reported above are consistent with the ones observed by means of other experimental methods: swelling experiments show an increase of the swelling ratio and preliminary iNMR imaging measurements suggest an increase of the porosity. It is likely that these features can be explained by the large size of the dextran chains $\left(\mathrm{M}_{\mathrm{w}}=4000\right)$ and to a smaller cross-linking ratio.

3.2. Evolution of the pNIPA macropore structure with temperature. As already mentioned pNIPA gels undergo a volume phase transition at a temperature of $\mathrm{T}_{\mathrm{c}}=34^{\circ} \mathrm{C}$ going from a swollen state below $T_{c}$ to a shrunken one above $T_{c}$. TPFM is used here in order to investigate the variation of the size of the macropore walls at increasing temperatures and its effect on the macropore size distribution. Figure 6 shows that the wall heterogeneities observed at $23^{\circ} \mathrm{C}$ decrease at $28^{\circ} \mathrm{C}$ and 
nearly disappear at $34^{\circ} \mathrm{C}\left(\mathrm{T}_{\mathrm{c}}\right)$. Interestingly, SRB remains adsorbed on the polymer chains despite the hydrophilic to hydrophobic character change at $\mathrm{T}_{\mathrm{c}}$. This feature can be explained by the slight lipophilic character of SRB already mentioned. As a result of the significant increase of the cryogel turbidity at $34^{\circ} \mathrm{C}$, the depth of analysis is reduced from $200 \mu \mathrm{m}$ at room temperature to about $100 \mu \mathrm{m}$. The slight decrease of the thickness of the walls between $23^{\circ} \mathrm{C}(12 \pm 2 \mu \mathrm{m})$ and $28^{\circ} \mathrm{C}$ $(10 \pm 2 \mu \mathrm{m})$ qualitatively agrees with the continuous diminution of the cryogel volume when the temperature increases ${ }^{32}$. At $34^{\circ} \mathrm{C}$, in the shrunken gel, the wall thickness is significantly smaller $(4 \pm 2 \mu \mathrm{m})$.
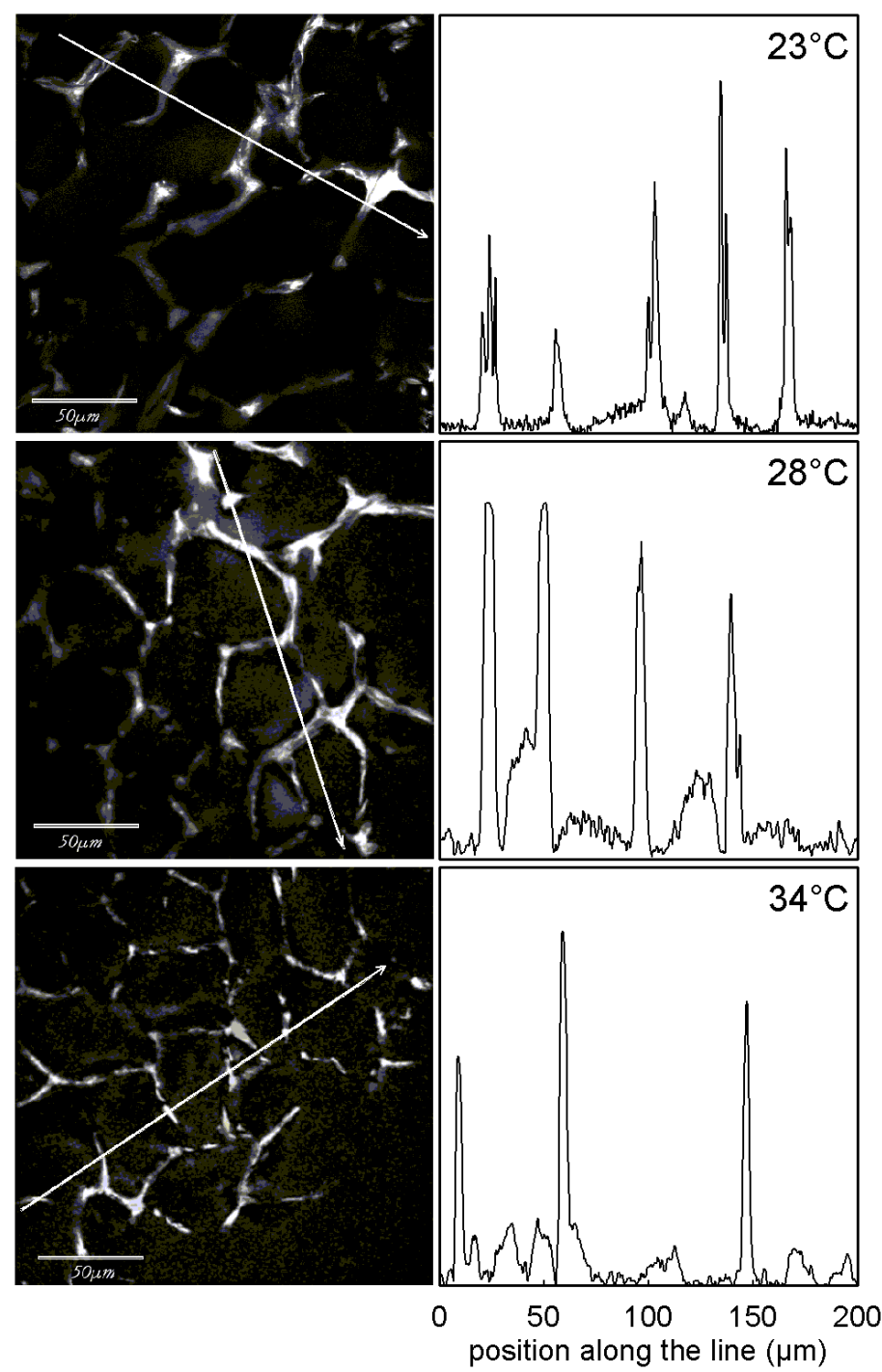

Figure 6. TPFM images (thickness $=2 \mu \mathrm{m}$ ) obtained for the pNIPA cryogel at a given sample depth $z$ (left) and (right) variation of the gray level intensity along the line at three different temperatures. The image and intensity curve at $23^{\circ} \mathrm{C}$ (same as Figure 3a) is reported here for comparison. Scale bar is $50 \mu \mathrm{m}$. 


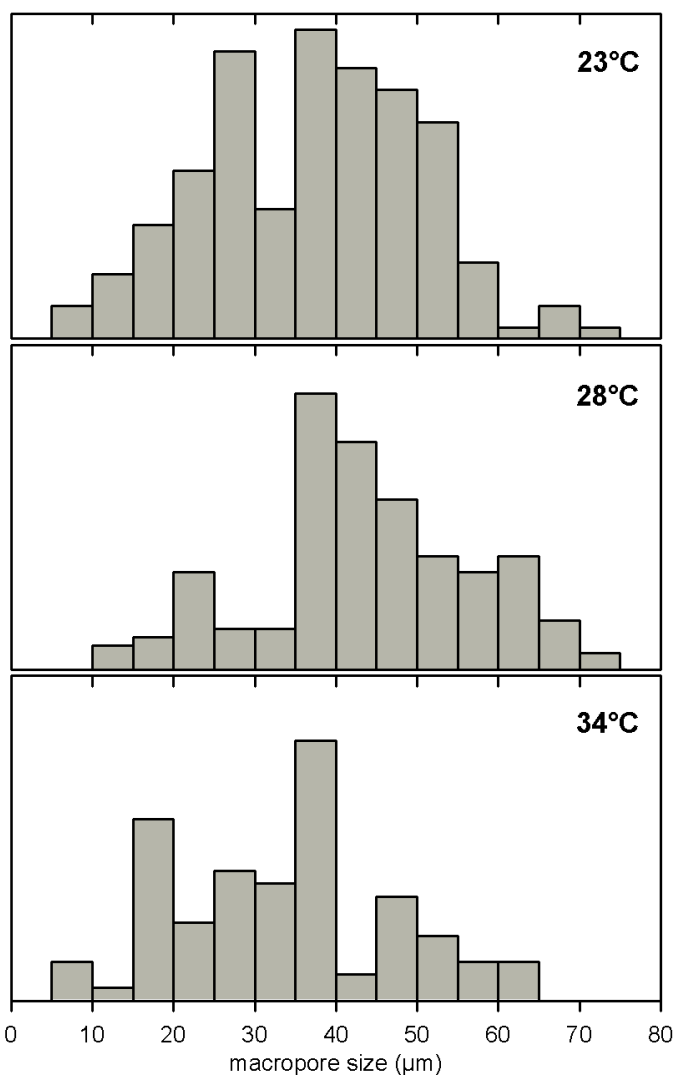

Figure 7. Macropore size distribution in the pNIPA cryogel at 23,28 and $34^{\circ} \mathrm{C}$.

In figure 7 , the macropore size distributions measured at 28 and at $34^{\circ} \mathrm{C}$ are compared to that obtained at $23^{\circ} \mathrm{C}$ (already shown in figure 5a at a larger size scale). The most interesting difference between the pore size distribution at 23 and $28^{\circ} \mathrm{C}$ concerns the left side (small pores) of the distribution: the relative amount of pores smaller than $37.5 \mu \mathrm{m}$ is significantly reduced when the position of the maximum remains unchanged. This feature suggests that the slight decrease of the cryogel volume between 23 and $28^{\circ} \mathrm{C}$ results not only from the weak decrease of the wall thickness but also from a partial collapse of small voids between neighbor walls.

At $34^{\circ} \mathrm{C}$ for the shrunken gel, the pore size distribution becomes broader but the maximum of the distribution remains unchanged. For this pNIPA cryogel, the swelling ratio is equal to 18.3 and 7.2 at $23^{\circ} \mathrm{C}$ and $34^{\circ} \mathrm{C}$ respectively ${ }^{32}$ leading to a volume decrease by a factor 2.5 close to the relative decrease of the wall thickness by a factor 3. Thus, the fact that the macropore size distribution remains nearly unchanged at $T_{c}$ agrees with macroscopic measurements of the swelling ratio.

\section{Conclusion}

Two-photon fluorescence microscopy associated with statistical image analysis and a well chosen fluorophore has proven to be a very well suited technique delivering excellent images of the 
structure in the bulk of macroporous polymer gels. Applied to the study of pNIPA and pHEMALLA-D cryogels and some of their copolymerized compounds, it provided reliable measurements of the wall thickness and pore sizes. It follows that TPFM could become the most suitable nonintrusive method for the characterization of swollen macroporous hydrogels.

\section{Acknowledgements}

Preparation of the cryogels investigated was performed in the context of the FP6-Network of Excellence: EXPERTISSUES, "Novel Therapeutic Strategies of Tissue Engineering of Bone and Cartilage Using Second Generation Biomimetic Scaffolds". Partial financial support by CICYTMAT2007-63355 is acknowledged.

\section{References}

(1) Hentze, H.-P.; Antonietti, M. Rev. Mol. Biotechnol. 2002, 90, 27-53.

(2) Burg, K. J. L.; Porter, S.; Kellam, J. F. Biomaterials 2000, 21, 2347-2359.

(3) Liu, X.; Ma, P. X. Ann. Biomed. Eng. 2004, 32, 477-486.

(4) Chen, G. H.; Hoffman, A. S. Nature 1995, 373, 49-52.

(5) Zhang, X.-Z.; Yang, Y.-Y.; Chung, T.-S.; Ma, K.-X. Langmuir 2001, 17, 6094-6099.

(6) Hirokawa, T.; Tanaka, T. J. Chem. Phys. 1984, 81, 6379-6380.

(7) Matsuo, E. S.; Tanaka, T. J. Chem. Phys. 1988, 89, 1695-1703.

(8) Chen, J.; Park, H.; Park, K. J. Biomed. Mater. Res. 1993, 44, 53-62.

(9) Patel, V. R.; Amiji, M. M. Pharm. Res. 1996, 13, 588-593.

(10) Ho, M.-H.; Kuo, P.-Y.; Hsieh, H.-J.; Hsien, T.-Y.; Hou, L.-T.; Lai, J.-Y.; Wang, D.-M. Biomaterials 2004, 25, 129-138.

(11) Wood, C. D.; Cooper, A. I. Macromolecules 2001, 34, 5-8.

(12) Sayil, C.; Okay, O. Polymer 2001, 42, 7639-7652.

(13) Safrany, A. Nucl. Inst. and Methods B 2005, 236, 587-593.

(14) Lozinski, V. I.; Plieva, F. M.; Galaev, I. Y.; Mattiasonn, B. Bioseparation 2002, 10, 163-188.

(15) Plieva, F. M., Karlsson, M.; Aguilar, M.-R.; Gomez, D.; Mikhalovsky, S.; Galaev, I. Y. Soft Matter 2005, 1, 303-309.

(16) Plieva, F.; Huiting, X.; Galaev, I. Y.; Bergenståhl, B.; Mattiasson, B. J. Mater. Chem 2006, 16, 4065-4073.

(17) He, X.J.; Yao, K.; Shen, S.; Yunet, J. Chemical Engineering Science. 2007, 62, 1334-1342.

(18) Lozinsky,V. I.; Galaev, I. Y.; Plieva, F.M; Savina, I.N.; Jungvid, H.; Mattiasson, B. Trends in Biotechnology. 2003, 21, 445-451.

(19) Plieva, F.M.; Galaev, I. Y.; Mattiasson, B. J. Sep. Sci. 2007, 30, 1657-1671. 
(20) Ritman, E. L. Annu. Rev. Biomed. Eng. 2007, 6, 185-208.

(21) Van Vlierberghe, S.; Cnudde, V.; Dubruel, P.; Masschaele, B.; Cosijns, A.; De Pape, I.; Jacobs, P. J. S.; Van Hoorebeke, L.; Remon, J. P., Schacht, E. Biomacromolecules 2007, 8, 331-337.

(22) Savina, I. N.; Cnudde, V.; D'Hollander, S.; Van Hoorebeke, L.; Mattiasson, B.; Galaev, I. Y.; Du Prez, F. Softmatter 2007, 3, 1176-1184.

(23) Behravesh, E.; Jo, S.; Zygourakis, K.; Mikos, A. G. Biomacromolecules 2002, 3, 374-381.

(24) Appel, R.; Xu, W.; Zerda, T.W.; Hu, Z. Macromolecules 1998, 31, 5071-5074.

(25) Tomita, Y.; Kubis, N.; Calando, Y.; Tran A.; Meric, D. P.; Seylaz J.; Pinard, E. J Cereb Blood Flow Metab. 2005, 25, 858-867.

(26) Denk, W.; Strickler, J. H.; Webb, W. W. Science 1990, 248, 73-76.

(27) Daria, V.; Nakamura, O.; Palmes-Saloma, C.; Kawata, S. Jpn. J. Appl. Phys. 1998, 37, L959L961.

(28) Rubart, M. Circ. Res. 2004, 95, 1154-1166.

(29) Mertz, J. Current Opinion in Neurobiology. 2004, 14, 610-616.

(30) Vérant, P.; Serduc, R.; van-der-Sanden, B.; Rémy, C.; Vial, J.C. J. Cereb. Blood Flow, Metab. 2007, 27, 1072-1081.

(31) Vérant, P.; Serduc, R.; van-der-Sanden, B.; Rémy, C.; Ricard, C.; Coles, J. A.; Vial, J.-C. J. Biomed. Opt. 2008, 13, 011002.

(32) Perez, P.; Plieva, F.M.; Alberto Gallardo, A.; San Roman, J.; Aguilar, M.R.; Morfin, I.;

Ehrburger-Dolle, F.; Bley, F.; Mikhalovsky, S.; Galaev, I. Y.; Mattiasson, B.

Biomacromolecules. 2008, 9, 66-74.

(33) Bölgen, N.; Plieva, F.; Galaev, I. Y.; Mattiasson, B.; Piskin, E. J. Biomater. Sci. Polymer Edn. 2007, 18, 1165-1179.

(34) Huault, T. DEA Report 2006, http://www-lsp.ujf-grenoble.fr/IMG/html/rapport_Thomas.html

(35) Kasnavia, T.; Vu, D.; Sabatini, D. A. Ground Water 1999, 37, 376-381.

(36) Yem, S. Master Report 2006, http://www-lsp.ujf-grenoble.fr/IMG/html/SOUNY.html

(37) Vérant, P. Thesis 2006, http://www-lsp.ujfgrenoble.fr/IMG/pdf/Pascale_VersionFinaleThese.pdf

(38) Hirokawa, Y.; Jinnai, H.; Nishikawa, Y.; Okamoto, T.; Hashimoto, T. Macromolecules 1999, 32, 7093-7099.

(39) Hirokawa, Y.; Okamoto, T.; Kimishima, K.; Koizumi, S.; Aizawa, K.; Hashimoto, T. Macromolecules 2008, 41, 8210-8219. 